\title{
O PROJETO ECLESIOLÓGICO DO VATICANO II
}

\author{
Dom Benedito Beni dos Santos
}

O Vaticano II foi, antes de tudo, um concílio da Igreja. Pela primeira vez, na história da Igreja, estiveram representadas, em um concilio, todas as Igrejas locais, na variedade dos povos, das raças, das culturas, dos problemas e desafios. Nos concílios anteriores, estiveram representadas partes da Igreja. Foram ecumênicos porque realizados em nome da Igreja universal e expressaram a fé da Igreja universal.

O Vaticano II foi também um concílio sobre a Igreja. Segundo Paulo VI, ele respondeu à seguinte questão: Igreja de Deus, o que dizes de ti mesma? o Concílio tratou da Igreja em todas as suas dimensões e aspectos. Teve quatro objetivos: em primeiro lugar, apresentar uma noção clara da igreja, sua autocompreensão. Em segundo lugar, tratar da renovação da lgreja, chamada por João XXIII de aggiornamento. Em terceiro lugar, procurar a restauração da unidade dos cristãos, não como simples volta a um rebanho, mas como procura da plena catolicidade na diversidade de liturgias, de tradições, de espiritualidade e cárismas. Finalmente, tratar da presença da Igreja no mundo. $\mathrm{O}$ Concilio, de fato, procurou estender uma ponte entre a Igreja e o mundo moderno.

Além da eclesiologia, o Vaticano II elaborou também um novo projeto eclesiológico para a Igreja, que estava se preparando para entrar o terceiro milênio de sua existência. Neste milênio, a lgreja vai gastar ainda muito tempo e energia para colocar em prática o projeto eclesiológico do Vaticano II, não só no que se refere à unidade dos cristãos, ao diálogo inter-religioso, mas a tantos outros pontos. Na realidade, estamos ainda no início da realização do projeto. Os dois pilares desse projeto são a constituição dogmática Lumen Gentium e a constituição pastoral Gaudium et Spes. Na primeira, o Concilio trata da consciência da Igreja, da sua autocompreensão. Na segunda, trata da presença da Igreja no mundo. 
Para elaborar a sua eclesiologia e o seu projeto eclesiológico, o Vaticano II reuniu aquilo que de melhor houve, em sua experiência e reflexão, nos séculos passados. Reuniu também a própria experiência de celebrar um concilio, que foi ecumênico até mesmo sob o ponto de vista numérico. Não é sem razão que os analistas de Vaticano It costumam referir-se aos seus antecedentes históricos.

No desenvolvimento do projeto, o Concílio seguiu uma linha históricosalvífica: a Igreja como criação do Pai através da obra redentora do Filho no Espírito Santo. A Igreja, ao mesmo tempo, como fruto da salvação e como comunidade de graça e salvação.

Para falar da Igreja, o Concílio assumiu a perspectiva da fé, ou seja, a Igreja em relação a Cristo. O olhar do Concilio se dirigiu da Igreja para Cristo e de Cristo para a Igreja. Charles Journet, em sua obra L'Eglise du Verbe Incarné, afirma que os evangelhos registram três olhares sobre Jesus. Alguns lançaram sobre ele um olhar meramente humano. Não conseguiram ver nele mais do que um simples homem. Por isso, perguntavam: não é ele o carpinteiro? Seus irmãos e irmãs não moram aqui conosco? E escandalizavam-se dele ${ }^{1}$. Nessa perspectiva humana, outros viram nele um possesso do demônio ${ }^{2}$.

Alguns, porém, lançaram sobre ele um olhar humano mais profundo. Descobriram que ele era alguém cheio da sabedoria do Espírito e movido pelo Sopro divino. Acharam que ele era um grande profeta: Ellas, Jeremias ou até mesmo, João Batista que havia ressuscitado ${ }^{3}$. Os que lançaram sobre Jesus - olhar da fé descobriram a sua identidade íntima e puderam exclamar com Pedro: tu és o Messias, o Filho do Deus vivo! $!^{4}$. Ou com S.Tomé: meu Senhor e meu Deus $!^{5}$.

Ora, a Igreja, por causa dos sacramentos que celebra e enquanto continuadora da missão de Jesus pode ser considerada, em certo sentido, um

$$
\begin{aligned}
& { }^{1} \text { Cf. Mc 6, 2-3 } \\
& { }^{2} \text { Cf. Mc } 3,22 \\
& { }^{3} \text { Cf. Mt } 16,24 \\
& { }^{4} \text { Cf. Mt } 16,16 \\
& { }^{5} \text { Cf. JO 20,28 }
\end{aligned}
$$

10 Revista de Cultura Teológica - v. 12 - N. 48 - jul/set 2004 prolongamento da encarnação. Sobre a Igreja também são dirigidos diversos olhares. Numa perspectiva meramente humana, alguns não conseguem ver na Igreja mais do que uma instituição religiosa que desempenha determinadas funções sociais. Numa perspectiva humana mais profunda, existem aqueles que ficam impressionados com a organização da Igreja, com sua unidade e, sobretudo, com os seus membros, que são santos. Dizia Bérgson, os santos e os heróis não precisam falar, basta que existam. Sua simples existência é um apelo para nós. Finalmente, existem os que laçam sobre a lgreja o olhar da fé. Descobrem então que ela encerra um mistério; que ela é uma comunidade de graça e salvação. Este é o olhar do Concílio Ecumênico Vaticano II

$\mathrm{Na}$ impossibilidade de tratar de todo o projeto eclesiológico do Vaticano II, vou analisar, rapidamente, apenas seis aspectos: a eclesiologia de comunhão, a Igreja como contínua construção desde a sua origem, o ser relacional da Igreja, a Igreja como sacramento universal da salvação, a Igreja - povo missionário e, finalmente, a lgreja a serviço não só de seus membros, mas de todos os seres humanos.

\section{A ECLESIOLOGIA DE COMUNHÃO}

A comunhão eclesial não é fruto de um esforço voluntarista. É obra da graça. Tem sua origem e referência na Trindade Santissima.

A Trindade representa a concepção original que o cristianismo tem de Deus. Todas as religiões falam de Deus. Para o cristianismo, porém, Deus é um mistério de comunhão de três pessoas. A Trindade constitui, pois, a revelação plena e definitiva de Deus. Toda a revelação anterior de Deus, inclusive a do Antigo Testamento, é apenas uma revelação precursora da Trindade. A Trindade não é apenas um dos mistérios do cristianismo. Ela é o mistério. 0 único mistério. Todos os outros mistérios (encarnação, eucaristia) são apenas uma decorrência do mistério da Trindade.

A Igreja tem a sua origem na Trindade. Ela faz parte do projeto do Pai, concebido desde toda eternidade. Nasceu da missão do Filho e do Espírito enviados pelo Pai ao mundo. Sem esta dupla missão, a Igreja não existiria. Ela deve organizar-se por referência à Trindade. Trindade significa que Deus é 
Amor. É um mistério de comunhão. O Espírito Santo, que é o elo pessoal de amor entre o Pai e Filho, é também o protagonista da comunhão eclesial. Ele cria a comunhão na Igreja e a comunhão da Igreja com a Trindade. Missão do Espírito é unificar a Igreja para ela conformar-se a Cristo e realizar o projeto do Pai.

Para que a comunhão seja uma realidade na Igreja, são necessários instrumentos práticos de comunhão. Alguns já existem. Tem a sua origem no Novo Testamento. Por exemplo, o ministério petrino e a colegialidade dos bispos. Outros foram criados ou incentivados pelo Vaticano Il: as conferências episcopais, os conselhos de presbíteros, os conselhos de pastoral etc. Todos esses organismos de comunhão, como observa o Papa na carta apostólica Novo Millenio Ineunte, precisam estar envolvidos péla espiritualidade de comunhão. Sem ela, eles seriam semelhantes a corpos sem alma ${ }^{6}$.

A comunhão eclesial tem o seu centro na Eucaristia, como mostra Paulo no capítulo décimo da primeira Carta aos Coríntios. Para Paulo, beber e comer são atos de comunhão. Quem come da carne oferecida em sacrifício, entra em comunhão com o altar. Quem come a carne oferecida aos ídolos entre em comunhão com os demônios, pois os ídolos são obras deles. Quem participa da Eucaristia entra em comunhão com o Corpo do Senhor. É, pois, na Eucaristia que a Igreja se torna, em plenitude, o Corpo de Cristo

O carisma coordenador da comunhão eclesial é a caridade. Ela leva cada um a procurar a própria identidade na relação com o outro; a ver em cada um, um reflexo da Trindade e um depositário dos dons divinos, antes de tudo, para a comunidade.

\section{IGREJA, REALIDADE EM CONSTRUÇÃO}

A teologia sempre tratou da origem da Igreja. Falar da origem da Igreja é tratar da sua relação com Jesus. Algumas teses relativizam, porém essa relação. Consideram a Igreja simplesmente como um fruto da atividade evangelizadora de Cristo e dos Apóstolos. Outras vêem nela apenas a resposta

\footnotetext{
${ }^{6}$ Cf. $\quad$ n. 43
}

de fé ao anúncio apostólico do Ressuscitado. Outros ainda como conseqüência não prevista do anúncio do Reino. Jesus, dizem eles, pregou o Reino, e o que surgiu foi a lgreja.

A Lumen Gentium mostra que a Igreja, embora tenha nascido do mysterium Christi na sua totalidade, ela esteve em processo de gestação em toda a história da salvação. A LG repete as expressões de $\mathrm{S}$. Agostinho e outros Padres, que falam da lgreja que vem desde Adão, desde $\mathrm{Abel}^{7}$. A tese da Lumen Gentium é a seguinte: a Igreja foi prefigurada desde o início da criação. Foi preparada na história do povo de Israel. Foi fundada nos últimos tempos. Foi manifestada ao mundo no dia de Pentecostes ${ }^{8}$.

Foi prefigurada desde o início da criação. A Bíblia de fato se refere a alianças que Deus realizou não com um determinado povo, mas com representantes da humanidade: Abel, Noé. Destas alianças surgiram verdadeiras experiências religiosas de natureza comunitária. Algo dessas experiências (a adoração de Deus, a busca de salvação) passaram para a Igreja de Jesus Cristo.

Foi preparada na história do povo de Israel. Do antigo Israel, a Igreja herdou as Escrituras do Antigo Testamento. No início, eram essas as únicas Escrituras que a igreja possuia. Os primeiros cristãos, em suas assembléias, fizeram uma leitura cristológica do Antigo Testamento. Muita coisa da sinagoga passou também para a liturgia cristã. Do antigo Israel herdou também a lgreja o caráter sagrado da família. Por isso, não é de se admirar que o cristianismo primitivo, durante quase dois séculos, não tinha templos. A comunidade se reunia nas casas de familia. Quando o Novo Testamento fala da Igreja como templo de Deus, como casa de Deus, entende, com estas expressões, a comunidade reunida.

A Igreja foi fundada nos últimos tempos, isto é, no tempo do Jesus histórico e do Cristo pascal. Atos fundantes da Igreja foram a escolha dos Doze por referência a Israel, povo constituído de doze tribos; a oração dominical que Cristo ensinou aos discípulos e, sobretudo, a instituição da Eucaristia na véspera de sua morte. Ato fundante da Igreja foi também a experiência pascal. Desde que houve um grupo de homens e mulheres, que acreditou na ressurreição de Jesus, existe algo de novo com relação ao antigo Israel. A fé na 
ressurreição do Senhor fez com que a comunidade de seus discípulos se tornasse uma comunidade nova.

A lgreja foi manifestada ao mundo no dia de Pentecostes. Como mostra o livro dos Atos, antes de Pentecostes, a comunidade dos discípulos de Jesus estava parada, sem iniciativa, sem saber que rumo tomar. O dom do Espírito Santo transformou essa comunidade em movimento missionário e a manifestou ao mundo.

\section{O SER RELACIONAL DA IGREJA}

O Vaticano II apresentou a imagem de uma Igreja não fechada sobre si mesma, mas em relação. Em primeiro lugar, em relação com a Trindade, seu mistério e paradigma para a sua organização. Uma Igreja em relação com o mundo. Mundo entendido como totalidade da criação, da qual a humanidade é parte. Mundo também no sentido humano, ou seja, construído pelo ser humano: a familia, o trabalho, a política, a ciência, a técnica, a cultura.

A presença da Igreja no mundo significa que ela é sacramento universal de salvação. Significa também que ela é feita de realidades terrestres; que ela é uma dimensão do mundo. As alegrias e tristezas, as vitórias e insucessos do mundo, perpassam também a vida da Igreja. Inclusive as fraquezas e debilidades do mundo. Por isso mesmo, a Igreja não só chama o mundo à conversão, mas ela mesma sente necessidade de conversão.

Igreja em relação com as outras Igrejas e comunidades cristãs. $\mathrm{Na}$ perspectiva da eclesiologia de comunhão, a Igreja se percebe em comunhão, ainda que imperfeita, com todas as igrejas e comunidades cristãs.

Igreja em relação com as religiões. Algo das religióes - adoração de Deus, busca da salvação - está também presente na Igreja de Jesus Cristo. O diálogo interreligioso tem, para a Igreja, uma dimensão evangelizadora. O diálogo é sinal de que a Igreja reconhece valores importantes nas outras religiões e quer colaborar com elas para a construção da justiça, da fraternidade e da paz no mundo.

Igreja, enfim, em relação com a missão. Sua índole é missionária. Missão que não significa apenas atividades missionárias, mas esforço de inculturação do evangelho e da fé.

14 ReVISTA de Cultura TeOlógica - v. 12 - N. 48 - JUL/SEt 2004

\section{IGREJA, SACRAMENTO UNIVERSAL DE SALVAÇÃO}

A compreensão da Igreja como sacramento já havia se difundido pela teologia antes da realização do Concílio. Tornou-se uma das categorias principais da eclesiologia conciliar. É uma categoria adequada para exprimir a profunda ligação da Igreja com o mistério de Cristo. Categoria adequada para expressar os aspectos visíveis e invisíveis da Igreja. A visibilidade articulada com o mistério da Igreja, e o mistério articulado com a visibilidade. Categoria adequada também para designar a índole missionária da Igreja e, até mesmo, a Igreja como servidora da humanidade.

Sacramento é o sinal visível da graça invisível. Em cada sacramento, existe algo que os sentidos podem perceber. Mas, ao mesmo tempo, existe algo só perceptível através da fé. O sacramento é sinal pleno: não só indica, mas contém a graça. É sinal eficaz: comunica a graça.

O sacramento fonte é o Verbo Encarnado. Na humanidade de Cristo, que os olhos viam, estava presente e agindo a divindade, que os olhos não viam. Por isso mesmo, os atos da humanidade de Cristo são sacramentais. Ele nos comunicou a graça salvífica pela sua encarnação, pelo seu nascimento, pela sua pregação, pela sua morte e ressurreição.

A Igreja não é sacramento fonte. É sacramento universal da salvação em Cristo. Enquanto está unida a ele como seu corpo. Cristo torna-se presente e age salvificamente através da Igreja, que anuncia a sua Palavra e celebra os sinais sacramentais. Portanto em Cristo a lgreja é ao mesmo tempo instrumento e sinal de salvação

A Lumen Gentium dedicou todo um capítulo à vocação universal à santidade. A santidade é componente da sacramentalidade da Igreja. A santidade consiste na conformação a Cristo. Ser um retrato vivo de Jesus Cristo. Sem a santidade, o sinal de salvação, que a Igreja deve ser, torna-se um sinal opaco. É a santidade, isto é, a conformação a Cristo, que dá à Igreja a autoridade para evangelizar.

\section{IGREJA, POVO MISSIONÁRIO}

A constituição dogmática Lumen Gentium termina com uma breve referência à índole missionária da Igreja. Breve referência que, na verdade, é uma 
introdução a um texto posterior que trata, ampla e profundamente, da natureza missionária da Igreja: o Decreto ad Gentes. Tem o nome de "Decreto", pois além de apresentar a teologia da missão, descreve também a organização missionária da Igreja e apresenta algumas normas gerais. O Decreto está, pois, em continuidade com a Lumen Gentium.

Afirma o Decreto ad Gentes que a missão é a expressão do desígnio salvífico de Deus. É a manifestação pública da história da salvação.

A teologia sempre ensinou que a missão teve origem no mandato de Cristo: "Ide, anunciai o evangelho a toda criatura"9. O Decreto vai além; coloca a origem da missão na própria Trindade. A missão da Igreja nasceu da missão do Fitho e do Espírito, enviados pelo Pai ao mundo.

Historicamente, a missão começou no domingo de páscoa, quando Maria madalena e a outra Maria foram ao túmulo e o encontraram vazio. Logo, veio o anúncio querigmático que está na origem da nossa fé, na origem do cristianismo, dos evangelhos e de todo o Novo Testamento: Ele ressuscitou! A seguir, vem a missão: Ide anunciar aos seus discípulos! $!^{10}$. E elas foram apressadas fazer o anúncio aos discipulos que, segundo o evangeiho de Marcos, estavam tristes e chorando. Em Pentecostes, iniciou-se a missão Ad Gentes que continua até hoje.

A missão suscita as igrejas locais. A semente da Palavra de Deus, espalhada pelo missionário, germina em igrejas locais. Estas têm como finalidade, continuar a missão ${ }^{11}$. Portanto, o sujeito da missão não é o missionário isoladamente. É a Igreja, a comunidade local.

O Decreto ad Gentes sublinha também a dimensão pneumatológica da missão. Ela é realizada em obediência ao mandato de Cristo e envolvida pela caridade e graça do Espírito Santo ${ }^{12}$. A ação do Espírito precede, acompanha e dirige a missão ${ }^{13}$. É Ele que move os pés do missionário, como aconteceu em Pentecostes. Ele é também o primeiro missionário. Aquele que chega

${ }^{9}$ Cf. Mc 16,15

${ }^{10} \mathrm{Cf}$. Mc 16,17

${ }^{11}$ Cf. Ad Gentes n.6

${ }^{12}$ Cf. ibid. n.5

${ }^{13}$ Cf. ibid. $n 4$ antes de todos para preparar o terreno, espargindo as "sementes do Verbo" na expressão dos Padres Apologetas. Sem essa ação do Espírito, a missão seria super-estrutura, acréscimo acidental à vida e cultura do povo. Sem essa ação do Espirito, a missão não seria resposta a uma busca.

\section{IGREJA A SERVIÇO DE TODOS OS SERES HUMANOS}

A constituição pastoral Gaudium et Spes forma um todo com a Lumen Geuntium. Materialmente é o documento mais longo do Vaticano II. Com ele, o Concílio quis mostrar claramente que o caminho da Igreja passa pelo ser humano. A Gaudium et Spes apresenta, por assim dizer, a base antropológica da eclesiologia conciliar. A Igreja é Igreja do Verbo Encarnado. É, em certo sentido, a continuação da encarnação. Pela encarnação, o Filho de Deus, afirma a constituição pastoral, se uniu a cada ser humano ${ }^{14}$. Assim, a revelação de Deus é, ao mesmo tempo, revelação do homem.

Cristo revela, antes de tudo, a dignidade sagrada do ser humano. Ele possui uma vocação divina ${ }^{5}$. Encontra-se numa relação única com Deus. É seu filho não só no sentido de que Deus é criador de tudo o que existe. O ser humano é filho no Filho de Deus que se encarnou. Com seu mistério pascal, Jesus demonstrou ainda que a nossa condição definitiva não é morte. É a ressurreição

Ao entrar numa comunidade humana, o Fitho de Deus tornoli-se solidário a nós. Santificou as relações humanas. Usou as categorias humanas para nos falar do amor do Pai, para anunciar o seu projeto de justiça, de fraternidade e de paz ${ }^{16}$.

Com a Gaudium et Spes a Igreja dá mais um passo qualitativo na compreensão de sua missão. Ela está a serviço não só de seus membros, mas de todos os seres humanos, independente de raça, de religiáo, de regime político.

${ }^{14} \mathrm{Cf}, \mathrm{GS}$ n. 22

15 Cf. ibid.

${ }^{16}$ Cf. ibid. $n .32$ 


\section{CONCLUSÃO}

João Paulo II, na encíclica Dominum et Vivificantem afirma que o Concílio Ecumênico Vaticano II foi um verdadeiro pentecostes. E com razão. São Lucas, no livro dos Atos, descreve não apenas um pentecostes, mas quatro pentecostes sucessivos: o pentecostes da manifestação da lgreja ao mundo ${ }^{17}$; o pentecostes da Igreja de Jerusalém ${ }^{18}$; o pentecostes dos gentios ${ }^{19}$ e o pentecostes da Igreja de Éfeso ${ }^{20}$. Em cada um desses pentecostes, a missão da Igreja se alarga. Lucas quis demonstrar, com esse fato, que os pentecostes se repetem na vida da Igreja.

O Vaticano II fol de fato um novo Pentecostes: Nele, o Sopro Divino renovou a Igreja. Levou-a ao encontro do mundo moderno. Fez com que ela descobrisse novos aspectos de sua missão. Despertou nela o profetismo e o diálogo. Colocou-a a serviço de todos os seres humanos.

Dom Benedito Beni dos Santos é Doutor em Teologia Dogmática e Bispo Auxiliar da Arquidiocese de São Paulo.

\footnotetext{
17 Cf. At 2, 1-13

18 Cf. ibid. 4,31

19 Cf. ibid. $10,44-46$

${ }^{20}$ Cf. ibid. $19,6-7$
}

18 Revista de Cultura Teológica - v. 12 - n. 48 - jul/set 2004

\section{UMA ANÁLISE DA SOCIEDADE NO CAMINHO DO VATICANO II"}

\author{
Prof. Dr. Pe. Ney de Souza
}

\section{INTRODUÇÃO}

O período que antecede o Concílio Vaticano II revela uma sociedade repleta de mudanças. Em pouco tempo diversos acontecimentos trouxeram grandes transformações que afetaram a humanidade. $O$ evento convocado pelo Papa Pio IX o Concilio Vaticano I (1869-1870), não chegou ao seu fim devido à guerra franco-prussiana. Esse fato vem assinalar uma ruptura decisiva nas relações político-social e ético culturais que o êxito do conflito revelava. O fato particular é na realidade revelador de uma série de fenômenos que se pensava terem sido superados cinqüenta anos antes

A Revolução Industrial continuava a trazer inovações e, para estas, eram necessárias novas abordagens. A industrialização não só fez aumentar a produção de produtos existentes, mas introduziu novos. Seus efeitos eram rápidos e trouxeram uma revolução apesar destes produtos permanecerem fundamentais. Não era uma revolução do carvão ou do ferro, apesar destes produtos permanecerem fundamentais. Depois de 1870 , se iniciava a idade do aço e da eletricidade, do petróleo e da química.

1 Este texto foi apresentado na Semana Teológica da Pontificia Faculdade de Teologia Nossa Senhora da Assunção (18 de maio de 2004, Campus I e II). 